Tyndale Bulletin 69.1 (2018) 153-156

\title{
PAULINE LANGUAGE AND THE PASTORAL EPISTLES ${ }^{1}$
}

\author{
Jermo van Nes \\ (jermo.vannes@etf.edu)
}

After a short introduction explaining the highly disputed status of the Pastoral Epistles (PE or Pastorals) in New Testament studies, Part I ('The Linguistic Problem of the Pastoral Epistles') serves as a history of research on the so-called linguistic problem of the PE. Tracing its roots, Chapter 1 ('Origins of the Problem: Founding Figures') discusses some of the key figures in the emerging debate over the peculiar language of the $\mathrm{PE}$ in relation to the question of their authorship. Evanson in 1792 was probably the first to challenge the authenticity of Titus on the partial basis of its distinctive language. Schleiermacher in 1804 did the same with 1 Timothy, mainly for linguistic reasons, noticing especially a large number of unique words and twisted phrases. Eichhorn extended Schleiermacher's critical agenda in 1812, being the first to question the authenticity of all three Pastorals for their unusual language. One of the most comprehensive critiques on the authenticity of the PE came from Holtzmann in 1880. He developed a case for the literary homogeneity of the Pastorals and the impossibility of dating them within the lifetime of Paul. The final major contribution was made by Harrison in 1921, who marshalled the argument that the language of the Pastorals is predominantly unPauline. All of these founding figures in the history of authenticity criticism on the PE, however, encountered serious opposition from scholars who challenged the idea that the language of the Pastorals is atypical for Paul.

1 Jermo van Nes, 'Pauline Language and the Pastoral Epistles: A Study of Linguistic Variation in the Corpus Paulinum' (Ph.D. dissertation, Kampen Theological University / Evangelical Theological Faculty, Leuven, 2017); supervisors Professors Armin D. Baum and P. H. R. van Houwelingen. Published as Language and the Pastoral Epistles: A Study of Linguistic Variation in the Corpus Paulinum (LBS 16; Leiden Brill, 2018). 
Chapter 2 ('Constituents of the Problem: Linguistic Peculiarities') discusses all the major lexical and syntactic peculiarities that since the works of Schleiermacher, Holtzmann, and Harrison have constituted the quantitative part of the PE's linguistic problem. In terms of vocabulary, scholars usually point to five major idiosyncrasies: (1) hapax legomena, (2) lexical richness, (3) missing indeclinables, (4) compound words, and (5) semantic deviations, including Grecisms and un-Paulinisms. Hapax legomena, lexical richness, and missing indeclinables seem to be the most important lexical anomalies for exegetes. In terms of syntax, scholars usually point to four major peculiarities: (1) interclausal relations, (2) structural irregularities in terms of anacolutha, parentheses, and ellipses, (3) miscellaneous uses of $\dot{\omega} \varsigma$, articles, and prepositions, and (4) stylometric data based on univariate and multivariate statistics. Interclausal relations and structural irregularities seem to be the most noteworthy syntactic peculiarities. To what extent these lexical and syntactic idiosyncrasies in the Pastorals differ from the other Paulines continues to be debated. According to the majority of scholars, the Pastorals comparatively use more hapaxes, vocabulary types, missing indeclinables, and hypotactic clausal relations, but comparatively fewer anacolutha, parentheses, and ellipses. A vocal minority of exegetes, however, insist that there is as much variation in language use among the other Paulines. Some scholars even claim that there is disproportional variation among the Pastorals themselves.

Chapter 3 ('Solutions to the Problem: Authorship Hypotheses') concerns the qualitative part of the PE's linguistic problem, giving an overview of the most important authorship hypotheses that have been developed in order to solve the problem. A good number of scholars advocate that the PE were written during the life of Paul (orthonymity hypothesis), whether by himself or by a secretary. Some scholars argue that the language of the Pastorals is broadly similar to the other Paulines and consider the statistical analysis underlying the linguistic argument to be false. Those who do believe that the language of the Pastorals differs from the other Paulines attribute it to other factors, including the use of derivative words, preformed traditions, Paul's older age, individual addressees, different subject matter, time for composition, shift in writing style(s), and/or change of register. Probably the majority of scholars are convinced, however, that the Pastorals were written pseudonymously after Paul had died 
(pseudonymity hypothesis). Ever since the work of Holtzmann, many inseist that the PE form a literary unity and were composed by the same author. Some others find the hands of two or even three different authors in the Pastorals. Yet other scholars have the opinion that only parts of them are genuine (partial orthonymity hypothesis).

Part 2('The Linguistic Problem of the Pastoral Epistles Reconsidered') reassesses the linguistic problem of the PE. Chapter 4 ('Approaching the Problem: Methodological Considerations') questions the corporal and historical approaches of many previous studies on the linguistic problem of the PE. The suggested alternative is to undertake analysis from a strictly linguistic perspective. This proposed analysis uses a population model of authorship assuming the orthonymity of all undisputed Paulines to which each member of the disputed Paulines can be measured. It involves a quantitative and qualitative analysis, given the bipolar nature of the PE's linguistic problem. The quantitative analysis is informed by simple linear regression analysis, which is a widely used technique in inter alia statistical linguistics for modelling the relationship between variables. The qualitative analysis concerns a comparison of explanatory models for linguistic variation by contemporary classicists and linguists using Indo-European text corpora, and by New Testament scholars for the Corpus Paulinum. Possible objections, namely that many Paulines include post-Pauline interpolations and were written by co-authors and/or secretaries, are shown to have insufficient explanatory power to a priori dismiss such a comparative study of linguistic variation.

Based on the methodology outlined in Chapter 4, Chapter 5 ('Pauline Vocabulary: New Perspectives') offers a linguistic interpretation of the most prominent lexical peculiarities of the PE: (1) hapax legomena, (2) lexical richness, and (3) missing indeclinables. Quantitative analyses reveal that only 1 and 2 Timothy have significantly more hapax legomena than the other Paulines. Unlike the communis opinio, the Pastorals are not shown to exhibit a richer vocabulary, nor to use significantly fewer types of indeclinables than the other Paulines. For each of these lexical criteria, however, considerable (to be distinguished from significant) variation is found in the Corpus Paulinum, both among the undisputed and disputed Paulines. The qualitative analyses (partially) based on studies in modern classics and linguistics reveal that quotations, proper nouns, productivity, and age might have affected the use of hapax legomena in 
the Corpus Paulinum. Similarly, lexical richness is shown to be affected potentially by emotion, age, topic, and/or textuality (versus orality), while the use of particular indeclinables might be due to subjectivity, emotion, and/or textuality (versus orality). All of these factors suggest that lexical variation in the Corpus Paulinum need not necessarily be explained by author variation.

Chapter 6 ('Pauline Syntax: New Perspectives') offers a linguistic interpretation of the most prominent syntactic peculiarities of the PE: (1) interclausal relations, and (2) structural irregularities in terms of parentheses, anacolutha, and ellipses. Quantitative analyses reveal that the Pastorals have no significant or even considerably more hypotactic clausal relations in their texts than the other Paulines. Similarly, the Pastorals are shown not to have significantly fewer structural irregularities in comparison to other Paulines. Only considerably fewer anacolutha are found in 1 and 2 Timothy. Qualitative analyses based on methods from studies in modern classics and linguistics reveal that the overall (minor) variation found in the Corpus Paulinum for the use of interclausal relations and structural irregularities might have been affected by age, emotion, and textuality (versus orality). Such factors prove syntactic variation in the Corpus Paulinum is not necessarily explained by author variation.

Overall, only one of the five most important linguistic anomalies used by scholars to question the PE's authenticity over the past two centuries has proven to be significantly different in 1 and 2 Timothy. The variation found among the Corpus Paulinum for the other four idiosyncrasies is shown to be considerable, but not significant. This enables the conclusion that the language of the Pastorals, despite differing from other Paulines in some respects, is quite similar in many more respects. The overall linguistic variation found in the Corpus Paulinum is shown to be affected in particular by age, emotion, and textuality (versus orality). However limited the number of linguistic particularities and their interrelationship tested, the overall results of this study challenge the common scholarly assumptions that the language of the Pastorals is homogeneous, that it significantly differs from the other Paulines, and that it must necessarily be explained by author variation. Accordingly, the results of this study also call into question the common scholarly practice of disputing the PE's authenticity for linguistic reasons. 